\title{
Addiction et spiritualité
}

\section{Jean Martin}

Dr méd., membre de la rédaction

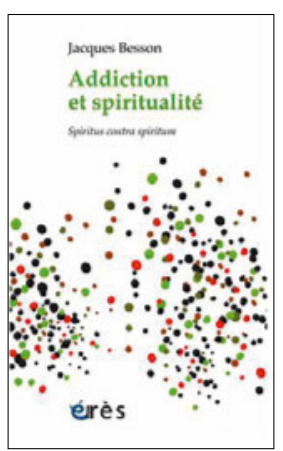

Notes

1 Le généticien américain Dean Hammer a publié un bestseller intitulé «The God Gene: How Faith is Hardwired Into Our Genes». Ses conclusions ont été contestées et il est très peu probable, dit Besson, «que la spiritualité laisse son hypercomplexité se réduire à quelques gènes».
Jacques Besson

Addiction et spiritualité

Spiritus contra spiritum

Toulouse: Editions érès; 2017

159 pages. $21.90 \mathrm{CHF}$

ISBN 978-2749255903

Jacques Besson est professeur de psychiatrie communautaire à la Faculté de médecine de Lausanne et au CHUV. Il s'est intéressé dès le début de sa carrière à l'alcoologie, aux Alcooliques Anonymes (AA), aux addictions en général et est responsable du dispositif vaudois y relatif - tout en manifestant un intérêt vif pour la dimension spirituelle de la santé.

Pour planter le décor: "L'intuition que nous vivons dans une société addictogène se vérifie au quotidien. Nous sommes dans une civilisation d'addiction générale au quantitatif, au numérique, à l'avoir et au prendre, dans un matérialisme étanche aux fraternités indispensables.» Il définit la spiritualité comme un besoin naturel et universel de sens et de cohérence avec soi-même, autrui et l'univers, qui peut être profane ou religieux. «Des études canadiennes et suisses sur les facteurs de rétablissement d'alcooliques ont permis de trouver une pluralité de facteurs protecteurs, au premier rang desquels figurait la spiritualité (Jésus, Bouddha, Mahomet) mais aussi des facteurs profanes.» Un diagnostic holistique doit se demander si «le patient possède des ressources potentielles, tant groupales que culturelles, incluant la spiritualité (...) Quel sens donne-t-il à sa destinée?» Les psychiatres américains se voient recommander d'effectuer une anamnèse spirituelle. En Europe, sommes-nous capables d'affronter notre difficulté à poser ces questions?

Médecine et spiritualité/religion. Pour C.G. Jung, la spiritualité est au cœur du rétablissement de l'alcoolique, il avait la conviction que notre monde va à sa perte s'il ne reconnaît pas les besoins spirituels. «Bien évidemment, un tel positionnement nous place aux confins de la médecine. Ses détracteurs y voient la mainmise possible de groupements fondamentalistes, en rupture avec la science. Ils craignent le passage d'une aliénation à une autre.» Pourtant: «S'il apparaît que la dimension spirituelle est bénéfique pour les patients, c'est un devoir pour la médecine d'intégrer ce champ dans ses préoccupations cliniques.» Pas simple... surtout en psychiatrie qui est en tension affichée avec la religion depuis ses débuts. Un chapitre est consacré aux hypothèses sur les effets de la spiritualité sur la santé travaux de Drewermann, Otto, Tillich, Antonosky, Lakoff. Les apports des neurosciences. Besson traite des neurosciences de l'addiction, notamment de la plasticité neuronale. Puis discute les trois «ordres» en médecine (physique, psychique et du «divin dans l'homme», de la sagesse), en présentant les positions de Platon, Pascal (qui parle de "cœur»), Teilhard de Chardin, du mystique suisse Maurice Zundel et du dalaï-lama (parlant lui de compassion).

Les travaux de Roger Sperry, Michael Gazzaniga et Andrew Newberg sont mentionnés à propos de neurothéologie. "Pour elle, science et religion n'ont aucune raison d'être incompatibles. Les questions spirituelles et religieuses sont naturelles, inscrites dans la biologie.» Sont abordées les dimensions génétiques et épigénétiques. En adressant aussi la question des mèmes (vus comme équivalent des gènes, mais pour la sélection des idées dans l'évolution culturelle). «La psychologie évolutionniste affirme que la spiritualité chez l'humain provient de mécanismes adaptifs, en vue de la survie» [1].

Névrose de civilisation - Besoin de construire du lien et du sens. Dans la conclusion, référence aux travaux de Viktor Frankl sur l'inconscient spirituel qui, lorsque refoulé, est source de névrose de civilisation, avec les trois symptômes que sont l'addiction, l'agression et la dépression. "L'addiction fonctionne comme une automédication, au prix d'une attaque des liens et du sens. La spiritualité elle contribue au contraire à la nécessaire cohérence.»

L'addictologie est un bon modèle pour l'écologie, souligne Besson en terminant. "Nous consommons les ressources de notre planète sur un mode parfaitement addictif. C'est sans doute pour cette raison qu'apparaît un mouvement d'écospiritualité, aspirant à un rapport équilibré entre humains et Terre nourricière.»

Aujourd'hui, après des décennies marquées par la science "dure» et un certain scientisme, c'est une démarche très estimable mais aussi délicate, y compris pour un académique de plein droit, d'investiguer les interfaces, les interactions, entre spirituel et médicothérapeutique. Démarche pourtant nécessaire. 